\title{
Inflammation, endothelial function and atherosclerosis in rheumatoid arthritis
}

\author{
Miguel A González-Gay*1 and Carlos González-Juanatey² \\ See related research by Sandoo et al., http://arthritis-research.com/content/14/3/R117
}

\begin{abstract}
Different techniques have proven to be useful in determining the presence of subclinical cardiovascular disease in patients with rheumatoid arthritis (RA). Doppler imaging with iontophoresis of acetylcholine and flow-mediated, endothelium-dependent vasodilation give information on endothelial dysfunction, an early step in the atherogenesis process. However, there is no good correlation between these two surrogate markers of cardiovascular disease in RA. A single determination of routine laboratory markers of inflammation does not seem to relate to endothelial function in RA. Further research is needed to determine whether microvascular endothelial function is a better predictor of cardiovascular outcome than macrovascular endothelial function in patients with RA.
\end{abstract}

Endothelial dysfunction is an early step in the atherogenesis process of rheumatoid arthritis (RA). In the previous issue of Arthritis Research \& Therapy, Sandoo and colleagues [1] reported a cross-sectional study performed on 99 unselected patients with RA to determine the presence of microvascular and macrovascular endothelial function in parallel with disease activity, individual cardiovascular (CV) disease risk factors, and global CV disease. The authors also longitudinally studied 23 patients who had RA and who started on anti-tumor necrosis factor-alpha (anti-TNF $\alpha$ ) therapy [1]. In the crosssectional study, markers of RA-related inflammation were not associated with microvascular or macrovascular endothelium-dependent function, and global CV disease risk inversely correlated with microvascular endotheliumdependent function. In the longitudinal study, only microvascular endothelium-dependent function showed

*Correspondence: miguelaggay@hotmail.com

'Department of Rheumatology, Hospital Universitario Marqués de Valdecilla,

IFIMAV, Avenida de Valdecilla s/n, E-39008, Santander, Spain

Full list of author information is available at the end of the article an improvement following 2 weeks of anti-TNF $\alpha$ treatment in comparison with baseline, but no association between change in endothelial function and change in inflammatory markers was evident. Considering these results, the authors concluded that classic $\mathrm{CV}$ disease risk may influence endothelial function more than disease-related markers of inflammation in RA. They stated that classic $\mathrm{CV}$ disease risk factors and anti-TNF $\alpha$ medication have different effects on microvascular and macrovascular endothelial function [1].

This interesting study raises a series of points that deserve to be addressed. First, endothelial dysfunction in RA is the result of a complex effect mediated by classic $\mathrm{CV}$ risk factors, genetic predisposition, chronic inflammation, pro-oxidative stress, a prothrombotic status, and metabolic abnormalities (such as insulin resistance or dyslipidemia) that to a greater or lesser extent may influence the development of this systemic pathological state [2]. The results reported by Sandoo and colleagues suggest that systemic markers of inflammation - erythrocyte sedimentation rate, C-reactive protein (CRP), and disease activity score using 28 joint counts (DAS28) and disease duration do not relate to endothelial function in microvascular and macrovascular vascular beds [1]. With respect to this, we feel that a single determination of routine laboratory markers of inflammation may not be useful to provide accurate information on the whole atherosclerotic burden associated with this chronic disease. In this regard, when we conducted a study to assess the association between inflammation measured by CRP values and carotid intima-media thickness (IMT) (another surrogate marker of $\mathrm{CV}$ disease) [3], we could not find a correlation between CRP at the time of disease diagnosis or at the time of the ultrasound study and the carotid IMT [4]. Nevertheless, the magnitude and chronicity of the inflammatory response measured by the average CRP values in patients with at least 5 years' disease duration correlated directly with the presence of atherosclerosis determined by carotid IMT [4]. Therefore, considering the results observed using carotid IMT, we think that an overall assessment of the values of biomarkers of inflammation over a prolonged period of 
time (that is, the mean value of CRP over at least 5 years' time), rather than a single determination of these biomarkers, might yield more useful information on the implication of these biomarkers of inflammation in the assessment of endothelial dysfunction of patients with RA.

Another important result derived from the study [1] was the poor correlation between different surrogate markers of atherosclerosis. This result is expected given that, in a study we conducted to determine whether a correlation between flow-mediated, endothelium-dependent macrovascular vasodilation and carotid IMT values exists, a correlation between these two surrogate markers of atherosclerosis was observed only in RA patients with a long disease duration (more than 7 years) [5]. Therefore, different techniques may provide information on different stages of the atherosclerotic disease [3]. Unlike laser Doppler imaging with iontophoresis of acetylcholine or flow-mediated, endothelium-dependent vasodilation (which give functional information on endothelial function), carotid ultrasound allows the identification of structural morphological damage that was reported to predict CV events in RA [6,7].

An unexpected result from the study by Sandoo and colleagues [1] was the absence of change of flow-mediated, macrovascular, endothelial-dependent function in response to 3 months of anti-TNF $\alpha$ treatment. This finding is in contrast to that of previous reports [8-10]. The authors' explanation of a better baseline macrovascular endothelial-dependent function in their cohort compared with previous series of RA patients undergoing antiTNF $\alpha$ therapy may be plausible, as treatment with antiTNF $\alpha$ may have less impact in RA patients who have an endothelial function similar to that of healthy individuals.

Finally, the authors highlight the importance of assessing endothelial function in more than one vascular bed. This conclusion is based on the observations that microvascular, but not macrovascular, endothelium-dependent function was associated with global CV disease risk algorithms and that only microvascular endotheliumdependent function changed following treatment with anti-TNF $\alpha$ [1]. At this point, replication of these observations by other investigators would be of great help to shed light on this matter.

Whether classic CV risk factors are more important than chronic inflammation to establish endothelial dysfunction in RA is, at this point, rather speculative. We feel that, as previously pointed out by Kitas and Gabriel [11], classic CV risk factors are important but not sufficient to explain all of the CV excess risk found in RA. We feel that additional research is needed to determine whether microvascular endothelial function is a better predictor of $\mathrm{CV}$ outcome than macrovascular endothelial function in patients with RA.

\section{Abbreviations}

anti-TNFa, anti-tumor necrosis factor-alpha; CRP, C-reactive protein; CV cardiovascular; IMT, intima-media thickness, RA, rheumatoid arthritis.

\section{Competing interests}

The authors declare that they have no competing interests.

\section{Authors' contributions}

MAG-G and CG-J made equal contributions to the conception and design of this editorial. Both authors read and approved the final manuscript.

\section{Acknowledgments}

The studies of MAG-G have been supported by two grants from 'Fondo de Investigaciones Sanitarias'PI06-0024 and PS09/00748 (Spain). This work was partially supported by RETICS Program, RD08/0075 (RIER) from 'Instituto de Salud Carlos III' (ISCIII).

\section{Author details}

'Department of Rheumatology, Hospital Universitario Marqués de Valdecilla, IFIMAV, Avenida de Valdecilla s/n, E-39008, Santander, Spain. ${ }^{2}$ Cardiology Division, Hospital Lucus Augusti, c/ San Cibrao s/n 27003 Lugo, Spain.

Published: 19 July 2012

\section{References}

1. Sandoo A, Kitas GD, Carroll D, Veldhuijzen van Zanten JJCS: The role of inflammation and cardiovascular disease risk on microvascular and macrovascular endothelial function in patients with rheumatoid arthritis: a crosssectional and longitudinal study. Arthritis Res Ther 2012, 14:R117.

2. Gonzalez-Gay MA, Gonzalez-Juanatey C, Martin J: Rheumatoid arthritis: a disease associated with accelerated atherogenesis. Semin Arthritis Rheum 2005, 35:8-17.

3. Kerekes G, Soltész P, Nurmohamed MT, Gonzalez-Gay MA, Turiel M, Végh E, Shoenfeld Y, Mclnnes I, Szekanecz Z: Validated methods for assessment of subclinical atherosclerosis in rheumatology. Nat Rev Rheumatol 2012, 8:224-234.

4. Gonzalez-Gay MA, Gonzalez-Juanatey C, Piñeiro A, Garcia-Porrua C, Testa A, Llorca J: High-grade C-reactive protein elevation correlates with accelerated atherogenesis in patients with rheumatoid arthritis. J Rheumatol 2005, 32:1219-1223.

5. González-Juanatey C, Llorca J, González-Gay MA: Correlation between endothelial function and carotid atherosclerosis in rheumatoid arthritis patients with long-standing disease. Arthritis Res Ther 2011, 13:R101.

6. González-Juanatey C, Llorca J, Martin J, González-Gay MA: Carotid intimamedia thickness predicts the development of cardiovascular events in patients with rheumatoid arthritis. Semin Arthritis Rheum 2009, 38:366-371.

7. Evans MR, Escalante A, Battafarano DF, Freeman GL, O'Leary DH, del Rincón I: Carotid atherosclerosis predicts incident acute coronary syndromes in rheumatoid arthritis. Arthritis Rheum 2011, 63:1211-1220.

8. Hürlimann D, Forster A, Noll G, Enseleit F, Chenevard R, Distler O, Béchir M, Spieker LE, Neidhart M, Michel BA, Gay RE, Lüscher TF, Gay S, Ruschitzka F: Anti-tumor necrosis factor-alpha treatment improves endothelial function in patients with rheumatoid arthritis. Circulation 2002, 106:2184-2187.

9. Gonzalez-Juanatey C, Llorca J, Sanchez-Andrade A, Garcia-Porrua C, Martin J, Gonzalez-Gay MA: Short-term adalimumab therapy improves endo-thelial function in patients with rheumatoid arthritis refractory to infliximab. Clin Exp Rheumatol 2006, 24:309-312.

10. Kerekes G, Soltész P, Szucs G, Szamosi S, Dér H, Szabó Z, Csáthy L, Váncsa A Szodoray P, Szegedi G, Szekanecz Z: Effects of adalimumab treatment on vascular disease associated with early rheumatoid arthritis. Isr Med Assoc J 2011, 13:147-152.

11. Kitas GD, Gabriel SE: Cardiovascular disease in rheumatoid arthritis: state of the art and future perspectives. Ann Rheum Dis 2011, 70:8-14.

doi:10.1186/ar3891

Cite this article as: González-Gay MA, González-Juanatey C: Inflammation, endothelial function and atherosclerosis in rheumatoid arthritis. Arthritis Research \& Therapy 2012, 14:122. 